\title{
Como fazer exames com imagens ponderadas em T2 para o estudo do abdome superior?
}

\author{
Roberto Blasbalg, Renata Emy Ogawa, Daniel Nobrega da Costa, \\ João Frederico Luciano de Mello \\ Setor de Medicina Interna do Serviço de Ressonância Magnética do InRad/HC-FMUSP
}

Esta é uma pergunta com várias respostas. Existem várias alternativas, dependendo do que se quer como resultado final.

As opções atuais são as seqüências spin-echo baseadas em RARE (FSE - fast spin-echo, SSFSE - single shot fast spin-echo), as imagens ecoplanares (EPI-SE - echoplanar imaging spin-echo e EPI-GRE - echoplanar imaging gradient-echo recalling) e as híbridas (GRASE - gradient and spinecho). Elas podem ser feitas em apnéia ou com sincronização respiratória, com ou sem supressão de gordura (supressão química determinada pela freqüência ou por recuperação da inversão - STIR).

A literatura sobre o assunto é ampla; comparações de seqüências quanto à relação sinal/ruído, relação contraste/ ruído, prevalência de artefatos, duração do exame foram feitas, porém raramente é possível fazer uma equivalência entre as diversas alternativas quanto aos parâmetros utilizados. Usam-se tempos de eco diferentes, aplicam-se pulsos de supressão de gordura em um caso e em outro não, o número de excitações (NEX) é diferente e assim por diante.

Otimizadas as seqüências, a de melhor relação sinal/ ruído adquirida em um tempo aceitável é a FSE. Ela pode ser realizada em apnéia ou com o uso de sincronizador respiratório.

O uso do sincronizador respiratório permite utilizar matrizes de alta resolução e NEX altos, já que não há limitação pelo tempo de apnéia. É necessário que o paciente seja bem esclarecido, que tenha padrão respiratório regular no decorrer do tempo do exame, já que o aparelho adquire os dados sempre na mesma fase do ciclo respiratório. Como o tempo de aquisição da seqüência é maior (cerca de três a cinco minutos), há maior possibilidade de artefatos de movimentação, entre eles, o decorrente do peristaltismo intestinal, que pode ser minimizado com o uso de antiespasmódicos (por exemplo, escopolamina).

O estudo não sincronizado é limitado pelo tempo máximo de apnéia do paciente, que em média varia de 20 a 30 segundos. Perde-se resolução na matriz e, eventualmente, na espessura de corte, e o NEX é mínimo (1) para se realizar o menor número de apnéias possível. Pode-se dividir o abdome superior em vários "blocos" e em cada apnéia um bloco é examinado. Se o paciente realizar apnéias com amplitudes diferentes, partes dos órgãos podem deixar de ser estudadas ou estudadas duas vezes. Há tecnologia para contornar este último problema, por exemplo, o PACE (prospective acquisition correction), que adapta os "blocos" da programação do exame de acordo com a posição do diafragma no decorrer do tempo (é um tipo de sincronização respiratória mediada por seqüências de pulso do tipo gradient-echo 2D). No geral, essas aquisições são rápidas, com boa relação sinal/ruído e não necessitam que o paciente tenha respiração regular.

Nos casos de pacientes que não têm respiração regular, nem fazem apnéia (pacientes graves), pode-se usar o SSFSE, que é praticamente insensível à movimentação respiratória, porém apresenta borramento (blurring) devido ao seu trem de ecos tendendo ao infinito. Esta seqüência tem ótima sensibilidade para a detecção de lesões benignas (cistos e hemangiomas), porém baixa sensibilidade para detecção de lesões sólidas, entre elas, metástases.

As seqüências GRASE foram desenhadas para unir o alto sinal das seqüências spin-echo com a velocidade das EPIGRE, mas posteriormente foram criticadas por introduzirem artefatos das imagens ecoplanares nas imagens spin-echo. Atualmente são pouco usadas na prática diária. Trabalhos recentes tentam mostrar que os erros de fase e de desvio 
químico gerados não necessariamente prejudicam a sensibilidade e a acurácia do exame e o tempo deste é encurtado. Além disso, as relações sinal/ruído e contraste/ruído são boas. Também podem ser adquiridas em apnéia ou com sincronização respiratória.

As seqüências descritas anteriormente podem ser realizadas com ou sem supressão da gordura. A sua utilização melhora o dynamic-range (redimensiona a escala de cinzas) das imagens, além de minimizar artefatos de movimentação respiratória.

Atualmente, um novo grupo de ferramentas surgiu para beneficiar de maneira significativa os exames abdominais: as técnicas de aquisição paralela integrada (ASSET - GE; SENSE - Philips; IPAT - Siemens). Elas permitem reduzir o tempo do exame, diminuir o borramento das imagens diminuindo o trem de ecos, aumentar o volume estudado e/ou a resolução mantendo o mesmo tempo de exame. Po- dem ser usadas em todas as seqüências anteriormente descritas, necessitando apenas de bobinas compatíveis ou dedicadas. Entretanto, há perda de $40 \%$ de sinal, que pode ser compensada com o uso de bobinas dedicadas (de oito canais), que adquirem imagens com o dobro de sinal-ruído. Esse parece ser o rumo atual para a ponderação T2 no abdome superior.

Com base no exposto acima, são muitas as possibilidades de escolha da seqüência T2. Apesar da literatura favorecer as seqüências em apnéia, seja por maior reprodutibilidade, seja por permitir maior produção do serviço, nós ainda acreditamos ser necessária a aquisição de ao menos uma seqüência com sincronização respiratória no estudo do abdome superior. $\mathrm{O}$ uso de técnicas de aquisição paralela e de bobinas de múltiplos canais, e num futuro próximo, equipamentos de alto campo $(3,0 \mathrm{~T})$, com certeza trarão grandes benefícios. 